\title{
Effect of two methods of grilling on the oxidative rancidity and cholesterol oxidation in beef and chicken shawerma
}

\author{
By Khalid Al-Ismail \\ Department of Nutrition and Food Technology \\ Faculty of Agriculture-University of Jordan \\ Amman-Jordan \\ E-mail:khalis @ ju.edu.jo
}

\section{RESUMEN}

Efecto de dos métodos de asado sobre la rancidez oxidativa y la oxidación del colesterol en "shawerma" de ternera y pollo.

El efecto de dos formas de asado sobre la rancidez oxidativa de la grasa y la oxidación de colesterol en "shawerma" de ternera y pollo fue estudiado durante las tres primeras horas del proceso de asado. La rancidez oxidativa de la grasa fue medida por el índice de ácido tiobarbitúrico (TBA), mientras que el colesterol fue determinado evaluando la concentración de 7-cetocolesterol. No hubo efecto significativo $(p \leq 0.05)$ de la fuente de radiación utilizada en el proceso de asado sobre los índices de TBA o el contenido de 7-cetocolesterol. El grado de instauración de la grasa tuvo un efecto significativo $(p \leq 0.05)$ sobre los índices de TBA y el 7 -cetocolesterol. Los valores de TBA y 7-cetocolesterol para las dos formas de asado alcanzaron los máximos después de 30 minutos de calentamiento para luego permanecer relativamente constante durante el resto del tiempo del experimento.

PALABRAS-CLAVE: HPLC - Oxidación lipídica - "Shawerma" de pollo-"Shawerma" de ternera - 7-cetocolesterol - TBA.

\section{SUMMARY}

Effect of two methods of grilling on the oxidative rancidity and cholesterol oxidation in beef and chicken shawerma.

The effect of direct blue and charcoal radiation heat grilling on the oxidative rancidity of fat and cholesterol oxidation in beef and chicken shawerma was studied during the first 3 hours of grilling process. The oxidative rancidity of the fat was measured by thiobarbituric acid value (TBA), while that of cholesterol by evaluating the concentration of 7-ketocholesterol. No significant effect $(p \leq 0.05)$ of the source of the grilling radiation heat was found on TBA values or 7-ketocholesterol content. The degree of unsaturation of the fat had significant effect $(p \leq 0.05)$ on TBA and 7-ketocholesterol values. TBA values and 7-ketocholesterol for both samples grilled either by direct blue or charcoal radiation heat reached maximum values after 30 $\mathrm{min}$ of the heat treatment then they remained relatively constant throughout the rest time of the experiment.

KEY-WORDS: Beef shawerma - Chicken shawerma - HPLC Lipid oxidation - 7-ketocholesterol - TBA.

\section{INTRODUCTION}

Microbial activities are considered the major factor of foods alteration during storage and manipulation. However, when these activities are under efficient control, the foods alteration will be of chemical nature. Lipid oxidation is a principal chemical change of foods, which depends on the level of oxygen, degree of unsaturation of fatty acids, energy (heat/light) and metals. Lipid oxidation products are responsible for the development of rancidity by the production of low molecular weight compounds that cause undesirable flavors (Frankel, 1985; Frankel et al., 1987), thus affecting the quality and limiting the shelf life of food products. Cholesterol is also oxidized in similar reaction mechanisms to those observed of fatty acids. Many of the cholesterol oxidation products have adverse effect such as cytotoxicity and modifications of enzyme activity (Erickson et al., 1978; Sevanin and Petrson, 1986; Bosinger et al., 1993), atherosclerosis (Kumer and Singhal, 1991), carcinogenicity and mutagenicity (Ansari and Smith, 1979).

Meat is usually subjected to different methods of cooking to become edible and more digestible. However, the heat treatment could lead to the oxidation of polyunsaturated fatty acids (PUFA) as well as cholesterol. 7-ketocholesterol forms during the first stages of cholesterol oxidation process, resulting in amount higher to the main cholesterol oxidation products (COPs) (Nourooz-Zadeh and Appelqvist, 1988; Kim and Nawar, 1993). Therefore it can be used as a useful index for cholesterol oxidation (Rankin and Pike, 1993; Zunib et al., 1995). 7-ketocholesterol has been detected in dehydrated organ meat (Park and Addis, 1985) and heated tallow (Park and Addis, 1986). Rodriguez-Estrada et al. (1997) observed a decrease in 7-ketocholesterol in hamburger after different methods of cooking.

Thiobarbituric acid (TBA) value has been used as the major indicator of the oxidative rancidity in meat and meat products (Melton, 1983). It's believed that TBA test measures one (or more) of secondary products of PUFA oxidation (De Vore, 1988). TBA values increased in ground meat stored at refrigerated temperatures (Keskinel et al., 1964; 
Govindaragin et al., 1977; Caldironi and Bazann, 1982). Stored cooked meat at refrigeration temperatures showed also a rapid fat oxidation (Rhee, 1978; Igene et al., 1979). Shin et al. (1992) observed an increase in TBA values after cooking at high temperatures of pork.

Shawerma is a well-known product in the Middle East countries that is made from beef or chicken meat arranged in layers alternatively with animal fat on a skewer to form a conical shape. During grilling process a side of the meat cone is subjected to radiation heat. The grilled side is turned to the face of the operator and scraped, whilst another side of the meat cone surface is subjected to grilling.

This work aimed to study the effect of the intermittent grilling by blue and charcoal heat radiation on TBA and 7-ketocholesterol levels in beef and chicken shawerma.

\section{MATERIALS AND METHODS}

\subsection{Reagents and solvents}

5-cholestan-3ß-ol-7-one (7-ketocholesterol) was from Sigma Chemical Co. (St. Louis, MO) and 7-ketopregnenolone (5-pregnen-3 B-ol7, 20-dione) was from Steraloids (Wilton, $\mathrm{NH}$ ). Solid phase extraction (SPE) columns packed with $0.5 \mathrm{~g}$ florisil purchased from International Sorbent Technology LTD (MID Glamorgan U.K). n-Hexane and heptane (HPLC grade) were from Lab-Scan (Dublin, Ireland). 2-propanol, chloroform, methanol were of analytical grades.

\subsection{Shawerma preparation}

Shawerma is usually prepared as described by Pellet and Shadarevain, 1970. According to this method, beef or chicken meat is marinated in a mixture of onions, minced garlic, lemon juice, pepper, cinnamon, red vinegar, nutmeg, salt and cardamon seeds for 8-12 hours. The meat is then arranged in layers alternatively with animal fat on a skewer to form a conical shape with about $70 \mathrm{~cm}$ length and a diameter of about $35 \mathrm{~cm}$ at the top and $20 \mathrm{~cm}$ t the bottom. The skewer is then fixed to a grill. the grilling process is started by frequent rotation of the meat cone at an interval of 1-2 min for about 15 min to scald the entire surface of the meat cone. After that, the surface of a part of the meat cone is exposed to blue or charcoal radiation heat for a period of 10-15 min, while the rest part of the con surface is subjected to the surrounding air. After that, the skewer is rotated to grill the surface of another part and the grilled layer is then scraped by a special knife to be served for eating. With many hours the whole meat cone is grilled in successive runs of 10-15 min for each.
Commercial beef and chicken shawerma ( 5 for each treatment, i.e. 20 samples), grilled by direct blue or charcoal radiation heat, were collected from different local restaurants. In addition to the above samples, control samples of beef and chicken shawerma grilled by blue or charcoal radiation heat were taken during the first 3 hours of the grilling process $(30,60,120$ and $180 \mathrm{~min})$, whereby every sample were exposed to grilling only for $15 \pm 2 \mathrm{~min}$. The temperature of the meat surface during grilling either by blue or charcoal radiation heat was between 200 and $220^{\circ} \mathrm{C}$, while that surrounded by the air was between 45 and $50^{\circ} \mathrm{C}$.

\subsection{Lipid extraction}

Total lipid extraction was carried out according to the modified Folch method (Rodriguez-Estrada et al., 1997): Fifteen grams of ready to eat shawerma were added to $200 \mathrm{ml}$ of a $\mathrm{CHCl}_{3} / \mathrm{C}_{2} \mathrm{H}_{5} \mathrm{OH}$ solution (1:1, $\mathrm{v} / \mathrm{v})$, homogenized for 30 second and placed in an oven at $60^{\circ} \mathrm{C}$, and then $100 \mathrm{ml}$ of chloroform was added to the mixture. The mixture was again homogenized for $1 \mathrm{~min}$ and filtered. The filtrate was added to $100 \mathrm{ml}$ of $1 \mathrm{M} \mathrm{KCl}$ and was left overnight at $4^{\circ} \mathrm{C}$. After phase separation the chloroform phase was evaporated using rotary evaporator and the lipid fraction was stored at $-20^{\circ} \mathrm{C}$.

\subsection{7-Ketocholesterol enrichment}

The enrichment of 7-Ketocholesterol was carried out on a SPE florisil cartridge (Penazzi et al., 1995). $1.5 \mu \mathrm{g}$ of 7-Ketopregnenolone was added to $70-80 \mathrm{mg}$ of the extracted lipids. The mixture is then dissolved in $0.5 \mathrm{ml}$ of 2-propanol/n-heptane (2\%, $\mathrm{vol} / \mathrm{vol}$ ) and loaded onto an SPE florisil cartridge, which had previously washed with n-heptane. The cartridge was then washed with 2-propanol $/ \mathrm{n}$-heptane $(2 \%, \mathrm{vol} / \mathrm{vol})$ to remove triglycerides together with the most of the cholesterol. The cholesterol oxides were then eluted with $5 \mathrm{ml}$ acetone. The solvent was evaporated under nitrogen flow at $35^{\circ} \mathrm{C}$ and the residue was dissolved in $1 \mathrm{ml}$ 2-propanol/n-heptane (7\%, vol/vol).

\subsection{Thiobarbituric acid value (TBA)}

Thiobarbituric acid value (TBA) was carried out according to Fausatman et al., 1992) method. The results were expressed as $\mu \mathrm{g}$ malondialdehyde/g sample by multiplying the measured absorbance of the incubated samples with factor 7.8 (Johns et al., 1989). All the shawerma samples were analyzed for TBA values directly after grilling. 


\subsection{High pressure liquid chromatography (HPLC)}

High pressure liquid chromatography was used for quantitative determination of 7-ketocholesterol. The HPLC was conducted with a normal phase column procedure similar to that of Penazzi et al., (1995). HPLC was carried out on a Pye Unicam system equipped with PU 4020 variable wavelength detector, PU 4010 pump and a Varian 4270 integrator. The column was a Hypersil type (Thermo Quest, Runcorn, U.K), with $30 \times 3.9 \mathrm{~mm}$ i.d. and $10-\mu$ particle size. HPLC elution was carried out under isocratic condition with a mobile phase of 2 -propanol/n-hexane $(7 \%, \mathrm{v} / \mathrm{v})$ at a $1 \mathrm{ml} / \mathrm{min}$ flow rate.

\section{RESULTS AND DISCUSSION}

The scope of this work was to study the influence of direct blue and charcoal radiation heat grilling on the oxidative rancidity and cholesterol oxidation in beef and chicken shawerma. The oxidative rancidity was evaluated by TBA test, while cholesterol oxidation by evaluating the level of 7-ketocholesterol. The results are reported in Tables I, II and III. The

Table I

TBA values and 7-ketocholesterol of commercial beef and chicken shawerma grilled by direct blue heat or coal heat

\begin{tabular}{|c|c|c|}
\hline Samples & $\begin{array}{c}\text { TBA } \\
\text { ( } \mu \mathrm{g} / \mathrm{g} \text { tissues) }\end{array}$ & $\begin{array}{c}\text { 7-Ketocholesterola } \\
\text { ( } \mu \mathrm{g} / \mathrm{g} \text { lipid) }\end{array}$ \\
\hline $\begin{array}{l}\text { Blue heat grilled beef shawerma } \\
\text { (1) } \\
\text { (2) } \\
\text { (3) } \\
\text { (4) } \\
\text { (5) } \\
\text { Average }\end{array}$ & $\begin{array}{l}0.74 \pm 0.09 \\
0.56 \pm 0.07 \\
0.94 \pm 0.09 \\
0.73 \pm 0.09 \\
0.76 \pm 0.08 \\
0.74 \pm 0.07\end{array}$ & $\begin{array}{l}25 \pm 0.3 \\
2.8 \pm 0.4 \\
2.6 \pm 0.2 \\
3.2 \pm 0.3 \\
1.8 \pm 0.3 \\
25 \pm 0.3\end{array}$ \\
\hline $\begin{array}{l}\text { Coal heat grilled beef shawerma } \\
\text { (1) } \\
\text { (2) } \\
\text { (3) } \\
\text { (4) } \\
\text { (5) } \\
\text { Average }\end{array}$ & $\begin{array}{l}0.63 \pm 0.08 \\
0.75 \pm 0.07 \\
0.73 \pm 0.09 \\
0.87 \pm 0.07 \\
0.73 \pm 0.09 \\
0.74 \pm 0.09\end{array}$ & $\begin{array}{l}21 \pm 0.1 \\
3.2 \pm 0.3 \\
1.9 \pm 0.4 \\
26 \pm 0.3 \\
22 \pm 0.2 \\
24 \pm 0.3\end{array}$ \\
\hline $\begin{array}{l}\text { Blue heat grilled chicken shawerma } \\
\text { (1) } \\
\text { (2) } \\
\text { (3) } \\
\text { (4) } \\
\text { (5) } \\
\text { Average }\end{array}$ & $\begin{array}{l}1.31 \pm 0.09 \\
1.13 \pm 0.09 \\
0.88 \pm 0.09 \\
1.55 \pm 0.09 \\
1.33 \pm 0.11 \\
1.37 \pm 0.13\end{array}$ & $\begin{array}{l}4.3 \pm 0.3 \\
25 \pm 0.4 \\
4.7 \pm 0.2 \\
3.8 \pm 0.4 \\
4.2 \pm 0.3 \\
4.0 \pm 0.4\end{array}$ \\
\hline $\begin{array}{l}\text { Coal heat grilled chicken shawerma } \\
\text { (1) } \\
\text { (2) } \\
\text { (3) } \\
\text { (4) } \\
\text { (5) } \\
\text { Average }\end{array}$ & $\begin{array}{l}1.43 \pm 0.10 \\
1.35 \pm 0.08 \\
1.96 \pm 0.09 \\
1.34 \pm 0.11 \\
1.46 \pm 0.09 \\
1.51 \pm 0.08\end{array}$ & $\begin{array}{l}3.9 \pm 0.2 \\
4.7 \pm 0.1 \\
4.0 \pm 0.3 \\
3.9 \pm 0.3 \\
4.2 \pm 0.2 \\
4.1 \pm 0.3\end{array}$ \\
\hline
\end{tabular}

a Mean of two replicates. data in Table I show the TBA values and 7-ketocholesterol levels of the commercial beef and chicken shawerma samples. TBA values of the beef shawerma showed a narrow scatter (standard deviation=0.11), ranging from a minimum value of 0.56 to a maximum value of 0.94 with an average of $0.74 \mu \mathrm{g} / \mathrm{g}$. Chicken shawerma samples, however, showed a wider scatter of TBA values (standard deviation $=0.28$ ), ranging from 0.88 to $1.9 \mu \mathrm{g} / \mathrm{g}$ with an average of $1.37 \mu \mathrm{g} / \mathrm{g}$ meat. 7-ketocholesterol concentration, expressed in $\mu \mathrm{g} / \mathrm{g}$ on lipid basis, of these commercial samples was quite low and ranged from 1.8 to 3.2 with an average of $2.5 \mu \mathrm{g} / \mathrm{g}$ for the beef shawerma and from 2.5 to 4.7 with an average of $4.0 \mu \mathrm{g} / \mathrm{g}$ for chicken shawerma. Regarding the samples control treatment, the results are reported in figures II and III. The data show that the TBA and 7-ketocholesterol reached maximum values after the first run of grilling (after 15 min of scalding and 15 min of grilling) and they were significantly ( $p \leq 0.05)$ higher than those of the raw samples. The average TBA and 7-ketocholesterol values found after the first run in the chicken samples grilled by the used two methods of grilling were 4.3 and 3.1 times and in beef samples were 3.5 and 2.1 times, respectively greater than those of the raw samples. These results indicate that PUFA and cholesterol oxidation has taken place. However, the data also show that no further significant $(p \leq 0.05)$ changes in TBA or 7-ketocholesterol values of the grilled samples took place throughout the 180 min of the grilling process, i.e. they remained relatively constant. In spite of the expected variation in the actual grilling time of the commercial shawerma samples, TBA and 7-ketocholesterol values were not significantly $(p \leq 0.05)$ different from those of the samples of the control treatment. The constant TBA and 7-ketocholesterol values are worth to be noticed and interpreted. These values indicate that the long period of exposing the renewed surface of the meat to successive grilling had little or no effect on the oxidative rancidity and cholesterol oxidation of the inner parts of the meat cone. This is probably due to the absence of oxygen in the inner layers of the meat as a result of the moderate heating and the activity of the aerobic bacteria expected to be in the meat. In addition to that, the antioxidants activity of the added spices (Helle and Grete, 1995) during marination may also protect the oxidation of lipid components in the inner parts of the meat cone. The results also indicate that the surface of the other parts of the meat cone surrounded by the air at any time of the whole grilling process did not seem to have clear effect on lipid oxidation. This might be due to fact that the temperature of these parts was moderate and about $45-50^{\circ} \mathrm{C}$ and its exposure time to the surrounding air was relatively short (usually less than $60 \mathrm{~min}$ ). Under these conditions the rat of fat oxidation might be slow. Furthermore, Cholesterol 
Table II

TBA values of the ready to eat beef and chicken shawerma samples collected after $0,30,60,120$ and 180 min of the grilling process

\begin{tabular}{lccccc}
\hline & \multicolumn{5}{c}{$\begin{array}{c}\text { TBA values }(\mu \mathrm{g} / \mathrm{g} \text { tissues) } \\
\text { Time }(\mathrm{min}) \text { of grilling process }\end{array}$} \\
\cline { 2 - 6 } Sample & $\mathbf{0}$ & $\mathbf{3 0}$ & $\mathbf{6 0}$ & $\mathbf{1 2 0}$ & $\mathbf{1 8 0}$ \\
\hline Blue heat grilled beef & $0.2^{\mathrm{b}} \pm .04$ & $0.7^{\mathrm{C}} \pm .1$ & $0.7^{\mathrm{C}} \pm .08$ & $0.7^{\mathrm{C}} \pm .08$ & $0.7^{\mathrm{C}} \pm .08$ \\
\hline Coal heat grilled beef & $0.2^{\mathrm{b}} \pm .03$ & $0.7^{\mathrm{C}} \pm .09$ & $0.7^{\mathrm{C}} \pm .09$ & $0.7^{\mathrm{C}} \pm .09$ & $0.7^{\mathrm{C}} \pm .09$ \\
\hline Blue heat grilled chicken & $0.3^{\mathrm{b}} \pm .03$ & $1.2^{\mathrm{C}} \pm .11$ & $1.3^{\mathrm{C}} \pm .11$ & $1.4^{\mathrm{C}} \pm .07$ & $1.3^{\mathrm{C}} \pm .11$ \\
\hline Coal heat grilled chicken & $0.3^{\mathrm{b}} \pm .04$ & $1.3^{\mathrm{C}} \pm .09$ & $1.2^{\mathrm{C}} \pm .09$ & $1.4^{\mathrm{C}} \pm .09$ & $1.3^{\mathrm{C}} \pm .10$ \\
& & & & &
\end{tabular}

a Mean of two replicates.

b-c Means with different superscripts within the same category are different $(p \leq 0.05)$

Table III

7-ketocholesterol values of the ready to eat beef and chicken shawerma samples collected after $0,30,60,120$ and $180 \mathrm{~min}$ of the grilling process

\begin{tabular}{lcclll}
\hline & \multicolumn{6}{c}{$\begin{array}{l}\text { 7-Ketocholesterol }(\mu \mathrm{g} / \mathrm{g} \text { lipids) } \\
\text { Time (min) of grilling process }\end{array}$} \\
\cline { 2 - 6 } Sample & $\mathbf{0}$ & $\mathbf{3 0}$ & $\mathbf{6 0}$ & $\mathbf{1 2 0}$ & $\mathbf{1 8 0}$ \\
\hline Blue heat grilled beef & $1.2^{\mathrm{b}} \pm .4$ & $2.5^{\mathrm{C}} \pm 0.2$ & $2.5^{\mathrm{C}} \pm .4$ & $2.4^{\mathrm{C}} \pm .3$ & $2.6^{\mathrm{C}} \pm .4$ \\
\hline Coal heat grilled beef & $1.2^{\mathrm{b}} \pm .3$ & $2.6^{\mathrm{C}} \pm .4$ & $2.4^{\mathrm{C}} \pm .1$ & $2.3^{\mathrm{C}} \pm .2$ & $2.4^{\mathrm{C}} \pm .3$ \\
\hline Blue heat grilled chicken & $1.3^{\mathrm{b}} \pm .1$ & $3.8^{\mathrm{C}} \pm .3$ & $4.2^{\mathrm{C}} \pm .3$ & $3.8^{\mathrm{C}} \pm .4$ & $4.3^{\mathrm{C}} \pm .3$ \\
\hline Coal heat grilled chicken & $1.3^{\mathrm{b}} \pm .3$ & $4.0^{\mathrm{C}} \pm .4$ & $3.8^{\mathrm{C}} \pm .2$ & $4.2^{\mathrm{C}} \pm .3$ & $3.9^{\mathrm{C}} \pm .2$ \\
\hline
\end{tabular}

a Mean of two replicates.

b-c Means with different superscripts within the same category are different $(p \leq 0.05)$

exhibits high stability against oxidation at temperatures below $100^{\circ} \mathrm{C}$ (Kyoichi et al, 1993).

Thus, the major factor that leads to substantial lipid oxidation in the meat is the exposure to the radiation heat during the period of the actual grilling (10-15 min), since the meat surface is exposed to elevated temperatures $\left(200-220^{\circ} \mathrm{C}\right)$ and to oxygen. This means that the whole grilling process which takes many hours occurs in successive runs of 10-15 min for each. The temperature of the meat part conducted to grilling in each run does not exceed $50^{\circ} \mathrm{C}$ and with relatively low level of oxidation. Therefore, the lipid components during the grilling runs might be subjected to similar conditions of oxidation, which may explain the relatively constant values of TBA and 7-ketocholesterol in the grilled samples of the control treatment throughout the first 180 min of the grilling process (Tables II-III).

The results obtained from the commercial and the control treatment samples (Tables I-III) showed that there was no significant effect $(p \leq 0.05)$ of the method of grilling on TBA and 7-ketocholesterol values. This is might be due to the elevated temperatures of the two method of grilling which resulted in the decomposition of TBA and 7-ketocholesterol. In general, TBA and 7-ketocholesterol values of chicken shawerma were significantly $(p \leq 0.5)$ higher than those of beef samples. This finding might be attributed to the fact that chicken fat contains higher levels of PUFA, which are prone to higher level of oxidation compared to that of beef fat (Rhee, 1996) and they also accelerate cholesterol oxidation (Kim and Nawar, 1991).

Although Melton (1983) reported that the oxidative rancidity can be detected at TBA values of 0.3-1.0 $\mu \mathrm{g} / \mathrm{g}$ of beef and pork and 1-2 $\mu \mathrm{g} / \mathrm{g}$ of chicken, no rancid flavors were detected in the beef and chicken shawerma used in the present study as has been observed by the general organoleptic testing. This is probably due to the effect of cooking and spicing which 
could directly or indirectly affects the detection of the oxidative flavor (Fernandez et al., 1997).

Although the concentration of 7-ketocholesterol content in the shawerma samples were quite low compared to those reported cooked hamburger (Rodriguez et al, 1997), in refrigerated stored cooked ground meat (De Vore, 1998) and dehydrated egg powder (Sander et al, 1989). However COPS could be absorbed readily into the bloodstream (Emanuel et al, 1991), which may produce cytotoxic effect (Addis and Warner, 1991; Peng et al., 1979). Therefore, further studies are needed to elucidate accurately the level of COPs that could be used as a risk index for long-term toxicity.

\section{REFERENCES}

Addis, P.B. and Warner, G.J. (1991). The potential health aspect of lipid oxidation products in food in Free Radicals and Food Additives, p.77-119..

Ansari, G.A.S. and Smith, L.L. (1979): High performance liquid chromatography of cholesterol autoxidation products. J. Chromatogr. 175, 307-315.

Bösinger, S., Luf, W., Brandl, L. (1993). Oxysterols: Their occurrence and biological effect. Int. Dairy J, 3, 1-33.

Caldironi, H.A. and Bazan, N.G. (1982). Effect of antioxidants on malonaldehyde production and fatty acid composition in pieces of bovine muscle and adipose tissue stored fresh and frozen. J. Food Sci., 47, 1329-1332.

De Vore, V. R. (1988). TBA values and 7-ketocholesterol in refrigerated raw and cooked beef. J.Food Sci., 53, 1058-1061.

Emanuel, H.A., Hassel, C.A., Addis, P.B., Bergmann, S.D. and Zavoral, J.H. (1991). Plasma cholesterol oxidation products (oxysterols) in human subjects fed a meal reach in oxysterols, J. Food Sci., 56, 843-847.

Erickson, S. K., Matsui, S. M., Strewsbury, M. A., Cooper, A. D., Gordan, R. (1978). Effect of 25-hydroxycholesterol on rat hepatic 3-hydroxy-3-methylglutaryl coenzyme A reductase activity in vivo, in perfused liver, and in hepatocytes. Biol. Chem., 253, 4154-4164.

Faustman, C., Yin, M.C., Nader, D.B. (1992). Color stability, lipid stability, and nutrient composition of red and white veal. J. Food Sci., 57, 302-304.

Frankel, E.N. (1985). Chemistry of free radical and singlet oxidation of lipids. Prog. Lipid Res., 23, 197-221.

Frankel, E. N., Nash A. M., Snyder, J. M. (1987). A methodology study to evaluate quality of soybeans stored at different moisture levels. J. Am. Oil Chem. Soc., 74, 387-391

Fernandez, J., Perez-Alvarez, J.A., Fernandez-Lopez, J.A. (1997): Thiobarbituric acid test for monitoring lipid oxidation in meat. Food Chemistry, 59, 345-353.

Govindarajan, S., Hultin, H.O. and Kotula, A.W. (1977). Myoglobin oxidation in ground beef: Mechanistic studies. J. Food Sci., 42, 571-563.

Helle, L. M., Grete, B. (1995). Spices as antioxidants. Trends Food Sci. Technol., 6, 271-277

John, A.M., Birkinshaw, I. M., Ledward, D.A. (1989). Catalysts of lipid oxidation in meat products. Meat Sci., 25, 209-220.

Igene, J.O., Pearson, A.M., Merkel, R.A. and Coleman, T.H. (1979). Effect of frozen storage time, cooking and holding temperature upon extractable lipids and TBA values of beef and chicken. J. Anim. Sci., 49, 701-706.
Keskinel, A., Ayres, J.C., and Snyder, H.E. (1964). Determination of oxidative changes in raw meats by the 2-thiobarbituric acid method. Food Technol., 18, 223-229.

Kim, S.K. and Nawar, W.W. (1993). Parameters influencing cholesterol oxidation. Lipids, 28, 917-921.

Kumar, N. and Singhal, O.P.(1991). Cholesterol oxides and atherosclerosis: A review. J. Sci. Food Agric., 55, 497-510.

Kyoichi, O., Takehiro, K., Koji, Y., Michihiro, S. (1993). Oxidation of cholesterol by heating. J. Am. Oil Chem. Soc., 41, 1198-1202

Melton, S.L. (1983). Methodology for following lipid oxidation in muscle foods. Food Tech., 38, 105-111.

Nourooz-Zadeh, J., Appelqvist, L. A.(1988). Cholesterol oxides in Swedish foods and food ingredient. Butter and Cheese. J. Am Oil Chem. Soc., 65, 635-1641.

Park, S. W., Addis, P. B. (1985). HPLC determination of C-7 oxidized cholesterol derivatives in foods. J. Food Sci., 50, 1437-1441.

Park, S. W., Addis, P. B. (1986). Identification and quantitative estimation of oxidized cholesterol derivatives in heated tallow lipids in muscle foods. $J$. Agric. Food Chem, 34, 653-659.

Pellet, P.L. and Shadarevain, S. (1970). Food Composition, Tables for use in the Middle East, p. 68-78. 2nd Ed. American University of Beirut, Beirut.

Penazzi, G., Caboni, M. F., Zunin, P., Evangelisti, F., Tiscornia, E., Gallina, T. T., and Lercker, G. (1995). Routine HPLC determination of free 7-ketocholesterol in some foods by two different analytical methods. J.Am.Oil Chem. Soc., 72, 1523-1527.

Peng, S.K., Tham, P., Taylor, .B., Mikkelson, B. (1979). Cytotoxicity of oxidation derivatives of cholesterol on cultured aortic smooth muscle cells and their effect on cholesterol biosynthesis. Am. J. Clin. Nutr., 32, 1033-1042.

Rankin, S. and Pike, A. (1993). Cholesterol autooxidation inhibition varies among several antioxidants in an aqueous model system. J. Food Sci., 58, 653-655.

Rhee, K.S. (1978). Minimization of further lipid peroxidation in the distillation of 2-thiobarbituric acid test of fish and meat. J. Food Sci., 43, $1776-1881$

Rhee, K.S, Anderson, A.M., Sams, A.R. (1996). Lipid oxidation potential of beef, chicken and pork. J.Food Sci., 61, 8-11.

Rodriguez-Estrada, M. T., Penazzi, G., Caboni, M. F., Bertacco, G., Lercker, G. (1997). Effect of different cooking methods on some lipid and protein components of hamburgers. Meat Sci., 49, 365-375.

Sander, B. D., Addis, P. B., Smith, D. E. (1989). Quantification of cholesterol oxidation products in a variety of foods, J. Food Prot., 52, 109-114.

Sevanian, A., Peterson, A. R. (1986). The cytotoxic and mutagenic properties of cholesterol oxidation products. Food Chem. Toxicol, 24, 1103-1110.

Shin, H. K., Abugroun, H. A., Forrest, J. C., Okes. M. R., Judge, M. D. (1992). Effect of heating rate on palatability and associated properties of pr- and postrigor muscle. J. Anim. Sci, 71, 939-945.

Zunin, P., Evangelisti, F., Caboni, M. F., Giulia, P., Lercker, G. (1995). Cholesterol oxidation in baked foods containing fresh and powdered eggs, J. Food Sci., 60, 913-915. 